\title{
Correction to: An Example of a Right Loop Admitting Only Discrete Topologization
}

\author{
Vipul Kakkar ${ }^{1}$ (D)
}

Published online: 7 June 2019

(C) The National Academy of Sciences, India 2019

Correction to: Natl. Acad. Sci. Lett. (March-April 2019) 42(2):131-133

https://doi.org/10.1007/s40009-018-0701-7

Unfortunately, in the online published article, the first line of the abstract has been published incorrectly.

The abstract should read as follows:

Being motivated by Suvorov and Kryuchkov (Sib Mat Zh 17(2):471-473, 1976) and Suvorov (Sib Mat Zh 32(5):193, 1991), an example of a right loop admitting only discrete topologization is presented in this paper.

Publisher's Note Springer Nature remains neutral with regard to jurisdictional claims in published maps and institutional affiliations.

The original article can be found online at https://doi.org/10.1007/ s40009-018-0701-7.

\footnotetext{
Vipul Kakkar

vplkakkar@gmail.com

1 Department of Mathematics, Central University of Rajasthan,

Ajmer, Rajasthan, India
} 